\title{
BMJ Open Patient and public perception and experience of community pharmacy services post-discharge in the UK: a rapid review and qualitative study
}

\author{
Sarah Khayyat, ${ }^{1}$ Philippa Walters, ${ }^{2}$ Cate Whittlesea, ${ }^{3}$ Hamde Nazar (1) ${ }^{2}$
}

To cite: Khayyat $S$, Walters P, Whittlesea C, et al. Patient and public perception and experience of community pharmacy services post-discharge in the UK: a rapid review and qualitative study. BMJ Open 2021;11:e043344. doi:10.1136/ bmjopen-2020-043344

- Prepublication history and additional material are published online only. To view please visit the journal online (http://dx.doi. org/10.1136/bmjopen-2020043344).

Received 30 July 2020 Revised 13 January 2021 Accepted 10 February 2021
Check for updates

(c) Author(s) (or their employer(s)) 2021. Re-use permitted under CC BY-NC. No commercial re-use. See rights and permissions. Published by BMJ.

${ }^{1}$ Population Health Sciences Institute, Newcastle University, Newcastle, UK

${ }^{2}$ School of Pharmacy, Newcastle University, Newcastle, UK

${ }^{3}$ Research Department of Practice and Policy, UCL School of Pharmacy, University College London, London, UK

Correspondence to

Dr Hamde Nazar;

hamde.nazar@newcastle.ac.uk

\section{ABSTRACT}

Objectives To investigate the perception and experience of patients and the public (PP) about community pharmacy (CP) services and other primary care services after hospital discharge back home.

Design and setting A rapid review and qualitative study exploring PP perceptions of primary care, focusing on $\mathrm{CP}$ services in the UK.

Methods A mixed-methods approach was adopted including a rapid review undertaken between 24 April and 8 May 2019 across four databases (MEDLINE, EMBASE, PsycINFO and CINAHL). Semistructured interviews were then conducted investigating for shifts in current PP perception, but also nuanced opinion pertaining to $\mathrm{CP}$ services. A convenience sampling technique was used through two online PP groups for recruitment. Thematic framework analysis was applied to interview transcripts.

Participants Any consenting adults $\geq 18$ years old were invited regardless of their medical condition, and whether they had used post-discharge services or not.

Results Twenty-five studies met the inclusion criteria. Patients were generally supportive and satisfied with primary care services. However, some barriers to the use of these services included: resource limitations; poor communication between healthcare providers or between patient and healthcare providers; and patients' lack of awareness of available services. From the 11 interviewees there was a lack of awareness of CP post-discharge services. Nevertheless, there was general appreciation of the benefit of CP services to patients, professionals and wider healthcare system. Potential barriers to uptake and use included: accessibility, resource availability, lack of awareness, and privacy and confidentiality issues related to information-sharing. Several participants felt the uptake of such services should be improved.

Conclusion There was alignment between the review and qualitative study about high patient acceptance, appreciation and satisfaction with primary care services post-discharge. Barriers to the use of CP post-discharge services identified from interviews resonated with the existing literature; this is despite developments in pharmacy practice in recent times towards clinical and public health services.

\section{Strengths and limitations of this study}

- This study is strengthened by its integrated methodology in which the qualitative study was built and informed by a rapid review of existing literature.

- The study provides a cross-sectional view of key perspectives of patients and the public about community pharmacy post-discharge services; it illustrates the views of healthy individuals, carers and patients with/without long-term conditions.

- The qualitative study is potentially limited by the small number of interviewees, however, a range of strategies were adopted to verify saturation of data, themes and theory.

- Potential regional variations were not evaluated as all participants were from the North-East of England.

The study did not consider the views of black and minority ethnic groups who may have different barriers to accessing services.

\section{INTRODUCTION}

There is recognition among healthcare commissioners and providers about the value of involving patients and the public (PP) in decision-making, managing their long-term conditions (LTCs), enabling health services to deliver better health outcomes, and reducing pressures and costs for the National Health Service (NHS). ${ }^{1}$ There is appreciation that patients can become 'experts' in living with their condition and, through collaboration with healthcare professionals, can play a role in the healthcare system as engaged agents to ensure that their own needs are appropriately met. ${ }^{2}$ Therefore, the involvement of PP in service design is considered important in developing advanced and more personalised healthcare services. The value of their views is also recognised in the evaluation and optimisation of services. ${ }^{3-5}$ Patient satisfaction of delivered services is an acknowledged parameter to measure when conducting service evaluation. ${ }^{6}$ The Economic, Clinical, and Humanistic Outcomes model incorporates 
patient satisfaction in the range of potential outcomes that can be measured when assessing effects of an intervention or service. ${ }^{78}$ The model, used in health services research, highlights that service effectiveness can be investigated from various perspectives. ${ }^{7}$

There has been a sustained interest in transfer of care (ToC) services, from hospital to home, in the past 20 years. ${ }^{9}{ }^{10}$ The goals of these services are to improve quality and quantity of communication between healthcare providers and provide out-of-hospital support and continuity of care $(\mathrm{CoC})$ between primary and secondary care. ${ }^{910}$ There are specific aims around medicines which include: ensuring that changes to medicines are followed up in community; improving patients' adherence with medicines especially for those starting new medicines; reducing medicines-related issues; and minimising any risk to patient safety especially for those who might experience an error or problem with their medicines following their hospital discharge. ${ }^{911} 12$ Community pharmacists have been recognised as appropriate in delivering care to patients following discharge from hospital, such as providing a medicines use review (MUR) or new medicines service consultation post-discharge. ${ }^{13-17}$ Recent systematic reviews report that pharmacist-led interventions allow medicines-related issues to be identified and rectified, ${ }^{13}$ which can result in an associated reduction in 30-day hospital readmissions. ${ }^{18}$ However, the evidence on the observed effects on 30-day readmissions was limited by heterogeneity in study design, analysis approach, degree of community pharmacist involvement and fidelity to the intended intervention. ${ }^{18}$ There is also limited evidence on the economic and humanistic benefits of such services.

In February 2020, the Department of Health and Social Care in England announced a new ToC service, the Discharge Medicines Service (DMS), to be initiated later in 2020. When patients are discharged, hospitals will digitally refer them to their community pharmacy (CP) for additional support and follow-up care on their new medicines. ${ }^{19}$ Although a range of previous ToC initiatives have been piloted or implemented in the UK, ${ }^{20-22}$ there is little evidence on patient perspectives including their perceived value of such services. This means that the impact of patient perspectives on the success of the new DMS service cannot be readily anticipated and considered in the implementation of this new service. In addition, according to the British Medical Research Council (MRC) framework, understanding patient responses to and interaction with an intervention is important to identify mechanisms of impact of that intervention; which is one of the key components of a process evaluation. ${ }^{23}$

In this study, we aimed to address the paucity of evidence around patient perspective on post-discharge services (such as the new DMS). The study incorporated a rapid review of the current literature about PP perception/experience of related primary care services to inform a qualitative investigation with PP about their perceptions and experiences with a specific focus on CP post-discharge services in the UK (ie, services provided to patients in a CP setting following their discharge from hospital).

\section{STUDY DESIGN}

Integration of different forms of data can dramatically enhance the value of the research where different integration approaches can be implemented at the design, methods, and interpretation and reporting of the findings. ${ }^{24}$ We have adopted an 'integration through building' approach where the results from one data collection procedure (rapid review) informed the data collection approach of the other qualitative investigation. ${ }^{24}$

\section{RAPID REVIEW \\ Methods of the rapid review}

The rapid review followed the systematic approach described in the Preferred Reporting Items for Systematic Reviews and Meta-analysis. ${ }^{25}$ We intended to use this type of review to synthesise knowledge of the targeted research question with the use of search strategies that make it easier to identify relevant papers. Components of the systematic review process were simplified or omitted to produce an evidence base in a timely manner. ${ }^{26}$ The full method used, including the search terms, is included in online supplemental file 1. In summary, the research question was focused on the perceptions and experiences of using primary care services by adult patients with LTCs in the UK. Adults with LTCs were chosen as they are considered to be the most prevalent users of primary care services and therefore have more extensive experience to report.

It was anticipated that very little empirical work existed specifically on CP post-discharge services, so this was widened to identify patient views on all primary care services that may be accessed after hospital discharge. It is recognised that healthcare systems vary worldwide, and this, with other factors such as culture and social norms, has an impact on the positioning of the patient in the system and subsequently their potential thoughts, feelings and perceptions of health and healthcare. Consequently, only studies conducted with patients in the UK were included in this review so findings could be more usefully related to the rollout of the DMS in England. One reviewer undertook the study selection and data extraction (SK); no risk of bias was undertaken. The search was conducted between 24 April and 8 May 2019 across four databases (MEDLINE-In-Process and Other Non-Indexed Citations, EMBASE, PsycINFO and CINAHL) for publications in English, and no publication date limit was considered.

\section{Results of the rapid review}

The rapid review identified 25 studies which met the inclusion criteria from the 395 identified from initial search. An overview of the rapid review results is provided in figure 1 . 


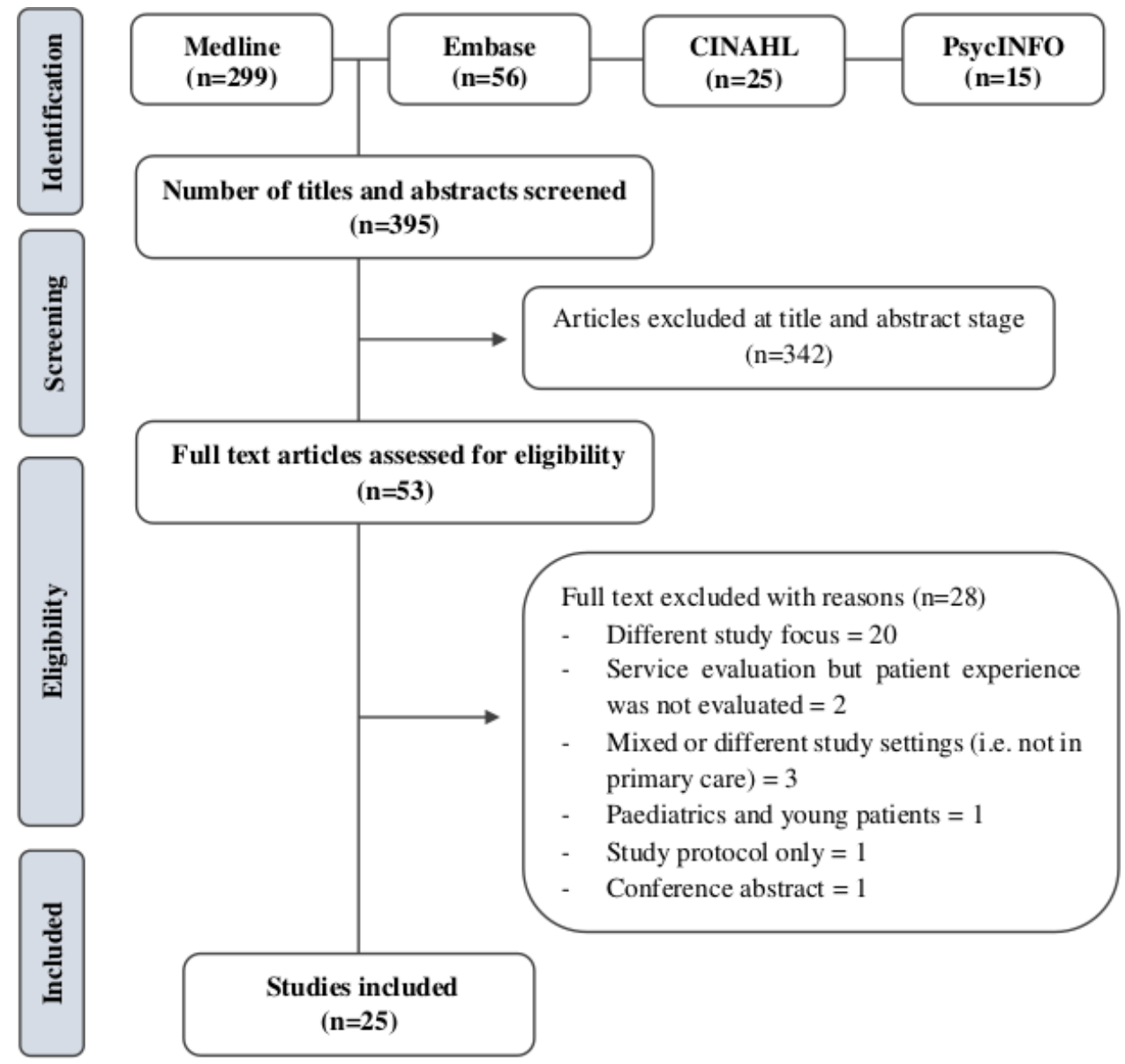

Figure 1 PRISMA flow diagram for the studies identified for the rapid review. PRISMA, Preferred Reporting Items for Systematic Reviews and Meta-analysis.

A summary of eligible studies is provided in online supplemental file 2. The identified studies had four different aspects:

- Patients' perspectives on the support provided by pharmacists in a CP or general practice setting. ${ }^{27-30}$

- Patients' perspectives on the use of a telehealth/telecare system. ${ }^{31-34}$

- Patients' perspectives on services provided by primary care teams to ensure CoC or ToC from a secondary to a primary care setting. ${ }^{2}{ }^{355-41}$

- Patients' perspectives on other primary care services provided by nurses or general practitioners (GPs) in primary care. ${ }^{42-49}$

Generally, these studies evaluated participants' awareness, acceptance, or appreciation of, and satisfaction with, the delivered services. Some studies also explored patients' perspectives on the availability of resources in the primary care setting to ensure their CoC. ${ }^{2} 273738$

Exploratory interviews and focus group approaches were commonly used to identify patients' perspectives of the services. ${ }^{2327424446}$ It was found that a qualitative study design helped not only in determining patients' level of acceptance, awareness of and satisfaction with the services delivered, but also in investigating barriers to, and facilitators for, using the services. ${ }^{2} 33638404248$
In those studies where a pharmacist, either in a $\mathrm{CP}$ or GP practice setting, was involved in the service, patients reported good to high satisfaction with the services. ${ }^{28-30}$ There was a report of low awareness of the services offered by community pharmacists ${ }^{27}$ and a preference to see the GP when there was a deterioration in health. ${ }^{30}$ Patients were found to be generally satisfied with telecare/telehealth $^{31-34}$ indicating the valuable potential for personalised digital care to help with self-management and problem solving. ${ }^{31} 33$ Some studies captured patients' experience of poor ToC due to poor informational continuity, ${ }^{36-38}$ and poor coordination of services. ${ }^{36-38}$ Other authors identified several aspects that contributed to achieving good CoC such as: informational continuity, team continuity and relational continuity. ${ }^{341}$ Patients were satisfied when they received joined-up care that was multiprofessional and attributed that to one or more of those aspects aforementioned relating to continuity. ${ }^{235} 3940$

\section{QUALITATIVE STUDY}

\section{Methods of the qualitative study}

To further investigate PP perception and experience around CP post-discharge care, semistructured faceto-face and telephone interviews were conducted with 
patients and members of the public between mid-July and mid-August 2019. A constructive approach has been adopted that facilitates capturing the lived experiences and perceptions of participants. ${ }^{50}$ This approach is inductive as it aims to develop an explanation or theory based on, and emerging from, the data, rather than a priori assumptions or theories. Therefore, knowledge is obtained by exploring and understanding the social world of the participants, and focusing on their views and interpretations. ${ }^{50}$ The Consolidated criteria for Reporting Qualitative Research checklist ${ }^{51}$ has been used to aid transparency in data collection, management and reporting (online supplemental file 3). All items are detailed within this study with the exception that repeat interviews were not conducted, and transcripts were not returned to participants for feedback or correction.

\section{Participant recruitment}

A convenience sampling technique was used through two online research groups to recruit patients and members of the public: 'Diabetes UK' (the UK's leading diabetes charity) and 'Voice' (Newcastle University and UK government-funded research network of UK and international citizens). A recruitment invitation was published on the organisations' websites requesting volunteers to contact the researcher directly.

Participant inclusion criteria were: adults $\geq 18$ years of age; able to communicate in English; able to provide informed consent to take part in the study; with no mental health problems and/or severe learning or hearing difficulties; based in the UK. To capture PP perception and experience, any member of the public who would benefit from CP post-discharge services was invited to contribute regardless of their medical condition (ie, if they have or have not any LTC). Participants were included in the study whether they had used CP post-discharge services or not; as this helped identify barriers for using such services. Those meeting all inclusion criteria were sent a formal email including a participant information sheet, consent form and demographic questionnaire. The participant information sheet defined the ToC from secondary to primary care settings, and explained potential CP services that patients might be offered/receive following their hospital discharge. Then, at the start of the interview, this definition was revisited to ensure participant's understanding of the meaning of CP post-discharge services.

\section{Data collection}

A semistructured interview topic guide (online supplemental file 4) was developed based on (1) findings of the rapid review (ie, knowledge gaps and topics covered during interviewing PP about similar services), (2) discussion between the research team, and (3) findings from previous interviews undertaken with healthcare providers contributing to such services, as part of an ongoing wider project on post-discharge ToC (unpublished work). The topic guide, with open and prompting questions, looked to explore specific areas of PP awareness, acceptability, experience and satisfaction of CP post-discharge services, and factors that helped or hindered them using such services. Participants were also encouraged to share further issues and thoughts not covered by the interview guide. Interviews were conducted in a private room at Newcastle University. Travel costs and refreshments were offered/paid for the participants.

A sampling matrix was used with the consideration of the type of participant (ie, healthy individual, carer or patients with/without LTC), gender and age of the participant. Participant recruitment continued until saturation had been achieved. Different models of saturation were considered at different levels of the research process. ${ }^{52}$ 'Data saturation' occurred as no new themes were generated after the ninth interview. Two more interviews were conducted to confirm that no new themes were emerging. 'Theoretical saturation' occurred as all constructs that explored CP post-discharge services were fully discussed with participants and represented by the data. 'Inductive thematic saturation' was considered when there were no new themes/codes emerging in the process of analysis. Following informed consent, all interviews were audiorecorded and transcribed verbatim. Transcripts were managed and analysed with the use of NVivo V.12 (QSR International, Melbourne, Australia).

\section{Data analysis}

Thematic framework analysis was used to analyse the data. ${ }^{503}$ A combination of thematic inductive and deductive analysis was employed. The former allowed flexibility in themes, ideas and explanations to emerge naturally from the data, and the latter approach meant that there was specific interrogation for the predefined categories derived from the rapid review. The six stages of framework analysis were followed: data familiarisation; coding process; developing an initial thematic framework; applying the thematic framework; reviewing data extracts and developing a framework matrix; and data interpretation. ${ }^{53}$ The initial coding process was conducted by SK, then, all authors discussed and checked the coding framework for accuracy and completeness. However, no inter-rater reliability was conducted.

Distinctive procedures were used as data analysis and collection proceeded; such as comparing and contrasting participants' responses with each other, memo writing and saturation. Searching for negative or deviant cases; frequent debriefing sessions; use of tactics to help ensure honesty in informants when contributing data; and providing a 'thick description' of fieldwork context were used to ensure the credibility and transferability of the findings. ${ }^{5455}$ The 'thick description' of the fieldwork context included descriptions of the setting, subjects, quotes, and other data around interpretation and synthesis to facilitate transferability to other contexts. ${ }^{56}$ No patient and public involvement was conducted to inform the research design, conduct, reporting or dissemination. 
Table 1 Participants' characteristics

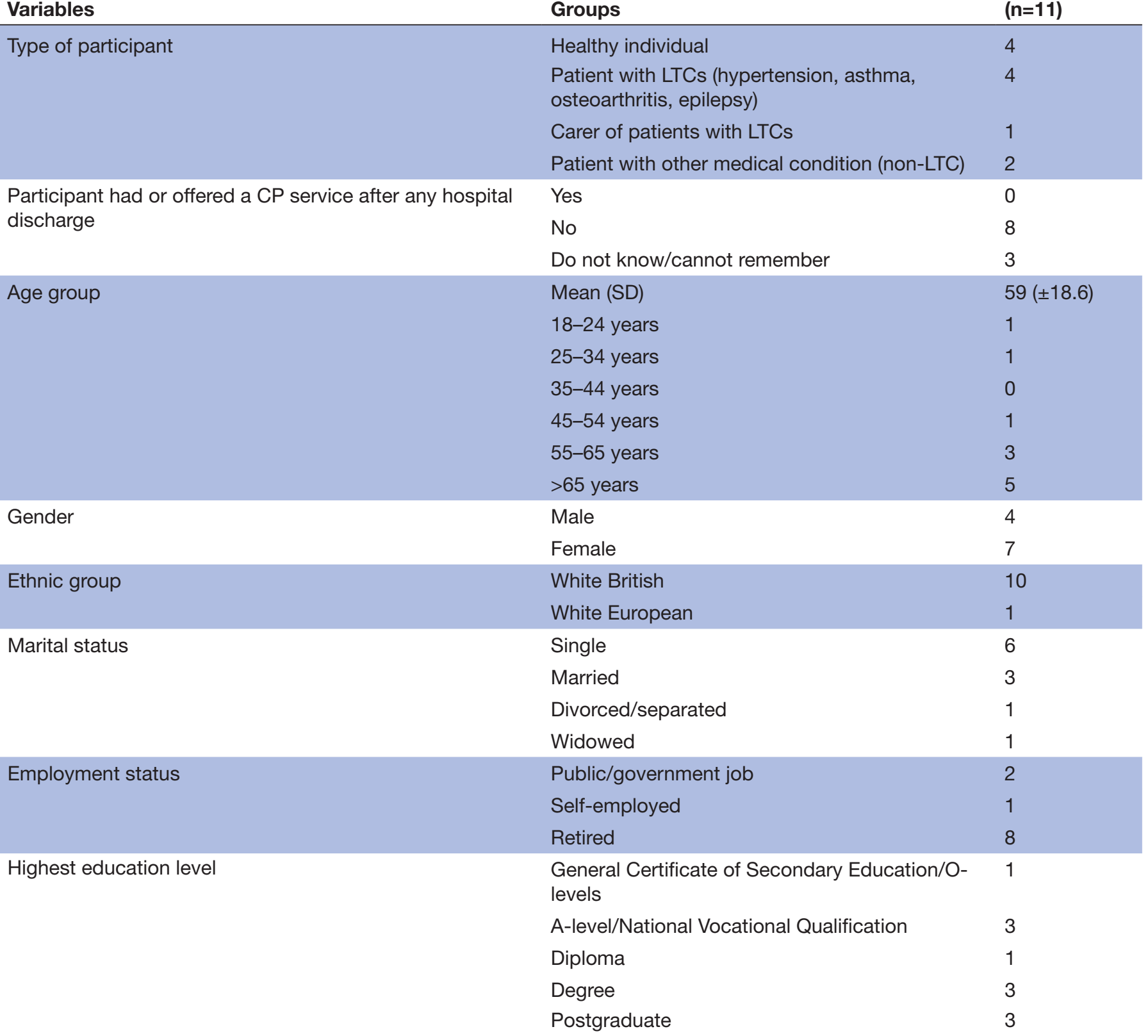

CP, community pharmacy; LTCs, long-term conditions.

\section{Results of the qualitative study}

A total of 14 volunteers met the inclusion criteria, of whom 11 were interviewed. The other three participants offered their initial interest, but did not respond to further contact. The mean average length of the interviews was $47 \pm 14 \mathrm{~min}$. All interviewees were from the North-East of England (recruited via 'Voice'); there were no volunteers recruited from 'Diabetes UK' research group. Characteristics of interviewees are detailed in table 1. Participants shared similar views on the use of CP post-discharge services regardless of their medical condition. The major themes and subthemes are presented in table 2 with illustrative quotes.

\section{Awareness of CP post-discharge services}

There was a general lack of awareness on the availability of CP post-discharge services. Around half of the participants knew nothing, though others had heard of, or knew a little information about such services from their GP, community pharmacists, the media or through a previous experience of a family member. The analysis also revealed that participants were not fully aware of all available CP 


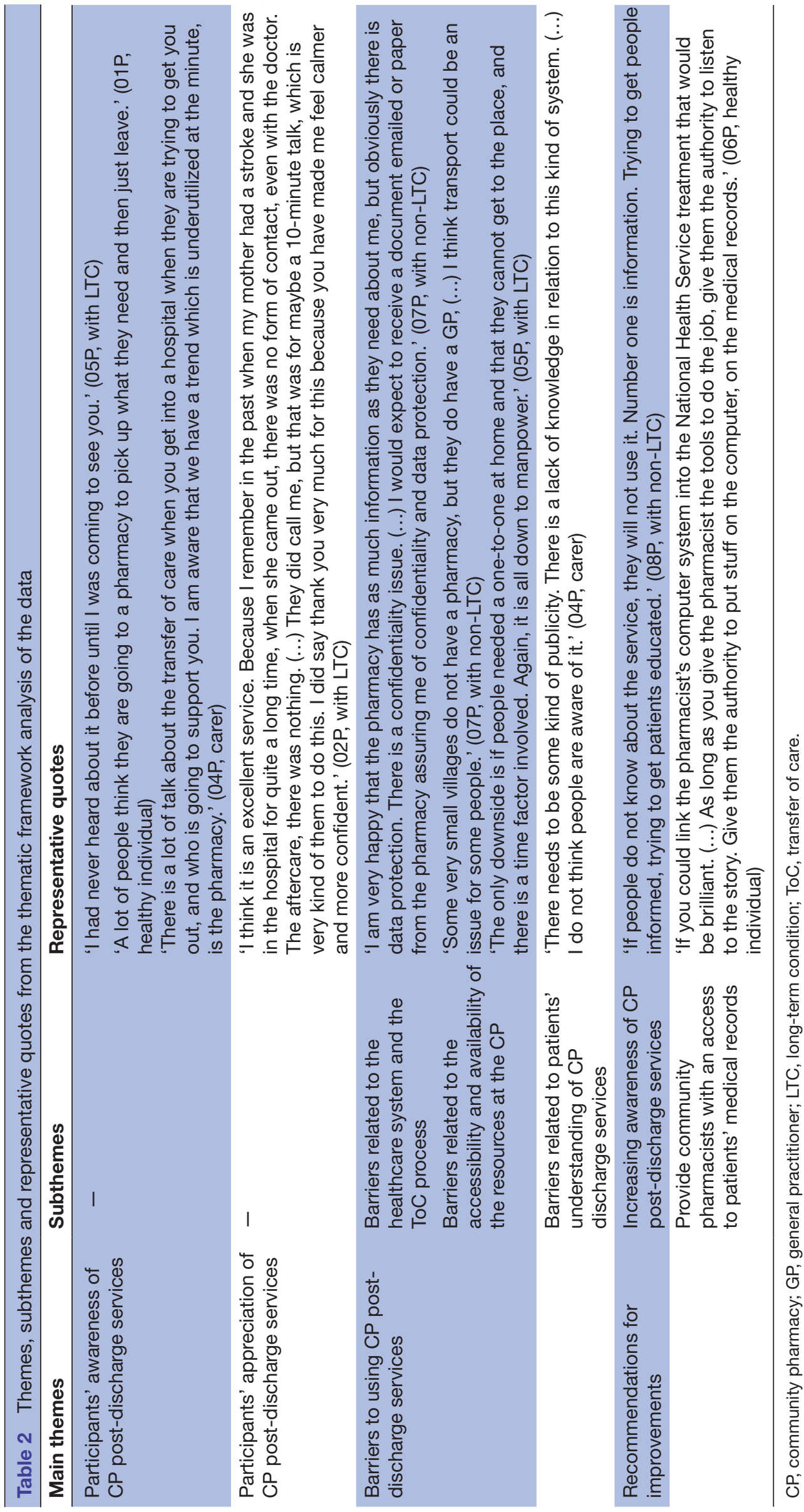


services and that half of them believed that the community pharmacists' role was mainly for dispensing medication. It was believed that community pharmacists could provide face-to-face or telephone counselling and a medicine review. The other described CP services were the medicine home delivery, smoking cessation, alcohol consumption services, services related to sexually transmitted diseases, and those providing blood pressure checks and hearing tests.

\section{Appreciation of CP post-discharge services}

Participants appreciated the concept of community pharmacy ToC services, and they would be willing to be referred to their CP if they needed post-discharge care. Participants believed that post-discharge services would provide many benefits for the healthcare system as well as for the discharged patients. A ToC service was appreciated as a form of communication between the hospitals and primary care (CPs and GPs), to inform about a patient's discharge and updated medication list. CP postdischarge services were also perceived to reduce pressure on hospitals and GP services as community pharmacists contributed to meeting healthcare demand. Participants articulated that such services had the potential to reduce the risk of errors around medicines which would have a patient safety and an economic value to the NHS. The benefits acknowledged for discharged patients included:

- Improved CoC following hospital discharge.

- Improved patient safety (as community pharmacists could monitor for any potential side effects or drugrelated issue).

- Improved psychosocial support for the discharged patients.

- Improved medication adherence through follow-up advice and counselling about medicines.

- Reduced hospital readmissions through additional support in primary care.

- CPs provide an accessible, convenient location to access care.

\section{Barriers to using CP post-discharge services}

Participants identified a range of potential barriers to the use of CP post-discharge services. These were related to (1) the healthcare system and the ToC process, (2) the accessibility and availability of the resources at CPs, and (3) the patients' understanding of CP post-discharge services. Examples of these barriers are provided in table 3 .

\section{Recommendations for improvements}

There were two recommendations for improvement highlighted by participants to improve/increase the use of CP post-discharge services which were: to increase PP awareness of the available services, and also to provide community pharmacists with access to patients' medical records.

Participants agreed that all healthcare professionals should be involved in raising the awareness of the CP post-discharge services. In the hospital, it was suggested the hospital staff (accident and emergency staff, doctors, nurses and pharmacy staff) should be involved in the discussion with the patient about post-discharge care. It was believed that consultants and other doctors in the hospital would play a major role in convincing patients about the benefits of CP post-discharge services.

In primary care, involving the GPs and advertising the service at general practices were suggested ways to increase the uptake of CP post-discharge services, especially as the patient-GP relationship was considered to be more widely established. Advertising the CP post-discharge service in the pharmacy itself was another option to raise awareness such that patients would know about post-discharge care prior to their hospital admission/discharge. Participants believed that all methods of communication with PP should be used in a comprehensive campaign, for example, email advertising; billboard marketing; press releases from local press and local authorities using the range of social media platforms, including information on the NHS website; and using traditional means of advertising such as posters and letterbox drops.

\section{DISCUSSION}

This rapid review identified high rates of patient acceptance, appreciation and satisfaction with primary care services post-hospital discharge. ${ }^{28-34}$ Patients believed that the service provided had improved their understanding of their treatment and disease condition. ${ }^{43} 45$ The review also highlighted the public lack of awareness of the availability of services provided in a CP setting following discharge from hospital. Although patients articulated an appreciation for such services, several barriers were identified related to CoC during transition and utilisation of the primary care services. Some barriers were related to healthcare systems and service providers such as resource limitations (eg, the availability of enough staff and associated time pressure in the primary care setting) ${ }^{238}$; the lack of support or information/advice from the healthcare providers $^{32} 33$; poor communication between healthcare providers or between patient and healthcare providers; poor coordination of transition of care between different healthcare settings ${ }^{3} 36384041$ and difficulty in making an appointment with the GPs. ${ }^{38}$ Other barriers to the use of primary care services, particularly CP services, were related to potential service users' beliefs and conditions such as: patients' lack of awareness of the available services or potential roles and capabilities of different healthcare providers in primary care $^{27}$; complexity of patient's condition; number of comorbidities and presence of LTCs. ${ }^{36} 3940$

The qualitative study captured PP appreciation of potential community pharmacist post-discharge services as beneficial for patients and the wider healthcare system. This reinforces the findings from previous studies in which patients appreciated services provided by pharmacists either in a CP or GP practice setting. ${ }^{28-30}$ Participants also related similar barriers and challenges to acceptance, 
Table 3 Barriers to using CP post-discharge services

\begin{tabular}{|c|c|c|}
\hline Type of barriers & Examples & Representative quotes \\
\hline $\begin{array}{l}\text { Barriers related to the } \\
\text { healthcare system and the } \\
\text { ToC process }\end{array}$ & $\begin{array}{l}\text { The different services provided locally which } \\
\text { confuse patients about what is available } \\
\text { The lack of a national standard ToC service* } \\
\text { Privacy and confidentiality issues related to } \\
\text { sharing information with the CP; as some patients } \\
\text { see community pharmacists as non-healthcare } \\
\text { professionals or because they feel their personal } \\
\text { information is too sensitive to be shared with their } \\
\text { CP }\end{array}$ & $\begin{array}{l}\text { 'We are bombarded with many new } \\
\text { systems, and there is another system on } \\
\text { top of another system. There is that much } \\
\text { confusion.' ( } 02 \mathrm{P} \text {, with LTC) } \\
\text { 'It might have been operating in some areas } \\
\text { for years, but it has not been operating in } \\
\text { the areas where I have lived.' (07P, with no } \\
\text { LTC) }\end{array}$ \\
\hline $\begin{array}{l}\text { Barriers related to the } \\
\text { accessibility and availability } \\
\text { of the resources at the CP }\end{array}$ & $\begin{array}{l}\text { Transport accessibility issues to the CP where } \\
\text { patients are too ill or housebound } \\
\text { Some CPs are not accessible for the elderly or for } \\
\text { patients with disabilities } \\
\text { Community pharmacists have time pressure and } \\
\text { therefore unable to provide post-discharge care } \\
\text { Community pharmacists cannot provide home } \\
\text { visits because of their shortage of staff }\end{array}$ & $\begin{array}{l}\text { 'Pharmacies that I have been out to, the } \\
\text { local ones, they do not have ramps or } \\
\text { disability access.' (01P, healthy individual) } \\
\text { 'There is very little time for pharmacists to } \\
\text { communicate with the person.' (02P, with } \\
\text { LTC) }\end{array}$ \\
\hline $\begin{array}{l}\text { Barriers related to patients' } \\
\text { understanding of CP post- } \\
\text { discharge services }\end{array}$ & $\begin{array}{l}\text { The lack of awareness of CP post-discharge } \\
\text { services } \\
\text { The lack of appreciation of the benefits of CP } \\
\text { post-discharge services, for example, some } \\
\text { participants believed that CPs do not provide } \\
\text { cognitive services/advices; access of care from } \\
\text { other healthcare professionals was preferred such } \\
\text { as GPs, practice nurses or the hospital doctor } \\
\text { Patients' low acceptability of seeing a community } \\
\text { pharmacist post-discharge may be due to a long } \\
\text { hospital stay so they do not want any additional } \\
\text { care, or they would be reluctant to change from } \\
\text { seeing their GPs as the first port-of-call, or they } \\
\text { do not have trust/good relationship with their } \\
\text { community pharmacists } \\
\text { Patients perceive that community pharmacists } \\
\text { have no knowledge of the patient's medical } \\
\text { history and no full access to the medical records; } \\
\text { therefore, they might not provide the required } \\
\text { support to hospital-discharged patients }\end{array}$ & $\begin{array}{l}\text { 'There is still a massive gap in terms } \\
\text { of understanding what the community } \\
\text { pharmacist can do. Many people think of it } \\
\text { as just a chemist's shop.' (04P, carer) } \\
\text { 'Diabetes affects people in different ways. } \\
\text { It would be wrong to expect the pharmacist } \\
\text { to be fully aware of exactly how diabetes } \\
\text { affects that person.' (10P, with LTC) } \\
\text { 'Older people might find it difficult not to } \\
\text { see their GP whom they know, like, and } \\
\text { trust. They might feel cast off and just } \\
\text { castaway to go and see the pharmacist } \\
\text { instead.' (07P, with no LTC) }\end{array}$ \\
\hline
\end{tabular}

${ }^{*}$ At the time of conducting the interviews, there was no national standard ToC service. However, DMS will be an essential national service for hospital-discharged patients on a new medicine.

CP, community pharmacy; DMS, Discharge Medicines Service; GP, general practitioner; LTC, long-term condition; ToC, transfer of care.

uptake and awareness of such services as those previously identified in the review. Indeed, these also resonate with the behavioural constraints around public awareness and expectations of CP identified in a recent Community Pharmacy Clinical Service Review undertaken by the King's Fund. ${ }^{57}$ Public perception and experience, and variation in services that CPs offer were listed as barriers to the wider provision of clinical services more generally through CP. Suggested solutions to address these were raising public awareness and the deployment of specific marketing campaigns. A recent study by Lam et al found that from the 100 inpatients informed about the opportunity for a discharge MUR with their community pharmacist post-discharge, only 5 actually took up this service and 78 stated that they had no intention to access this care.
The most common reasons were: their lack of perceived need for support with their medicines; their default reliance on the care provided by their doctors; or reduced capacity to self-present at the pharmacy due to their morbidity or limited mobility. Authors recommended the need for developing and consolidating the relationships between patients and their community pharmacists rather than marketing the specific services that can be offered. In this way, patients would benefit from a perceived sense of relational continuity which they have reported feeling from accessing care from their GPs. ${ }^{58}$ Another significant enabler would be the trust in, and promotion of $\mathrm{CP}$ services by other healthcare providers. The same review by the King's Fund identifies a lack of awareness by other healthcare providers of the contribution that community 
pharmacists can make, meaning that these stakeholders do not actively support uptake and acceptance of CP services. ${ }^{57}$ Ferguson et al also reported low engagement of hospital pharmacy staff promoting and offering CP post-discharge care to inpatients, due to their lack of understanding and appreciation of the potential benefit to patients of a CP intervention. ${ }^{21}$

This recent contribution to the understanding of how PP perceive primary care and CP services post-discharge, from both the literature and the qualitative study, bears significance on the potential uptake and success of the proposed national DMS. The interviews have shown that there are still some barriers related to the uptake of $\mathrm{CP}$ services, despite recent advancements in service provision in CP in England. Therefore, there is an emphasis on the need to involve different healthcare professionals from different settings to raise PP awareness of the value of CP skills and roles and provision of post-discharge services such as the new DMS. A recent realist synthesis highlighted how PP trust in hospital staff making referrals and coordinating post-discharge care, and the experience and attitudes of PP towards CP impact the willingness and uptake of CP services. ${ }^{59}$

There are many theoretical frameworks and conceptual models that can further our understanding of potential success of a new service implementation and adoption. Rogers offers one such conceptual model, which is that of Diffusion of Innovations. ${ }^{60}$ In this model, it is stipulated that there must be sufficient knowledge of the 'decisionmaking unit' (ie, the patient) to develop strategies of persuading engagement with the innovation (ie, the CP post-discharge services). The model also highlights a number of factors which govern the adoption process of an intervention. The 'relative advantage' of the intervention over other practices is one of the important factors. If patients do not appreciate the value or 'relative advantage' of the intervention, they are unlikely to engage and make a decision to adopt that intervention. According to the MRC framework, service designers, commissioners and policymakers need to identify contextual factors that should be addressed alongside the implementation and delivery of any intervention within a system. ${ }^{23}$ Otherwise, they risk the outcomes and ultimately success of that intervention. Rogers refers to poor implementation and adoption of a service as 'discontinuance', which is attributed to a range of factors. This includes: an individual decision to replace the adopted service by a better one; the misuse of a service which could have been beneficial for individuals if it had been used in the right way or dissatisfaction with the service performance. Service user's dissatisfaction might not be related to the quality of the service itself, but because the service was inappropriate for that individual and did not provide an adequate level of perceived relative advantage over alternative practices. ${ }^{60}$ Hence, discontinuance of a new service is an indication that the service might not have been appropriately implemented and normalised into service users' behaviours and health choices. In addition, a high rate of discontinuance is more likely when the service is less compatible with an individual's beliefs and past experiences. ${ }^{60}$ Therefore, based on Rogers's theory, ${ }^{60}$ service designers and implementers need to understand the wider beliefs / past experiences of PP with CP services, that is, lack of awareness and buy-in, and identify mechanisms, for example, ensuring services are recommended/initiated by healthcare professionals who are already entrusted by patients, to enhance the perceived relative advantage towards driving engagement and uptake. Regular monitoring and evaluations of the service's progress, providers' performance and patient satisfaction alongside service performance will best allow ongoing identification of challenges. These can be targeted and addressed to not only support sustainability of that service, but will also contribute to incremental change in PP perception over time. Previous recommendations around public awareness campaigns, and more sustainably, reinforcing the relationships between community pharmacists and the public, remain pertinent to overcome challenges that threaten the success and potential outcomes of both the DMS and other potential new clinical services in a CP setting. These recommendations, in addition to the factors identified in the Rogers conceptual model ${ }^{60}$ and MRC guidelines ${ }^{23}$ about the need to identify patient perspectives of any new service, would fundamentally apply in any international context where a new service is being proposed.

The study had a number of limitations. First, only one data abstractor and coder conducted the rapid review, and no risk of bias was undertaken. This is in line with the abridged nature of rapid reviews compared with those undertaken systematically. Second, the qualitative study is potentially limited by the small number of interviewees. However, a range of strategies were adopted to verify saturation of data, themes and theory. Third, potential regional variations in PP perspective of CP post-discharge services were not evaluated. All participants were from the North-East of England, even though we used a national research PP support group to recruit participants. Lastly, the study did not consider the views/experiences of black and minority ethnic groups who are generally underrepresented in their use of healthcare services. This is an important consideration in any service evaluation as they may have different barriers to accessing services such as language difficulties, and differing expectations, cultural and social norms that may affect how they seek out and engage with healthcare services. Overall, it is believed that transferability in this study is achieved as we sufficiently described the context of the fieldwork so that readers can evaluate the extent to which the study findings and conclusions are transferable to their settings, situations, people and times.

\section{CONCLUSION}

The review identified high rates of patients' acceptance, appreciation and satisfaction with primary care services post-discharge. These positive perceptions were 
confirmed by the subsequent qualitative study. A number of barriers to the use of $\mathrm{CP}$ post-discharge services were also identified from PP interviews which were similar to those identified from the review; there was no difference in patient perception of such services despite contemporary developments in CP practice. In general, participants appreciated potential CP post-discharge services as beneficial for patients and the wider healthcare system. However, awareness of CP services remains limited which will threaten the subsequent uptake and engagement of PP. Further research should establish the effectiveness of CP post-discharge services on patient's clinical/nonclinical outcomes as this will further evidence the value of such interventions to other healthcare professionals and PP. Also, determining other stakeholders' views (eg, service leaders, hospital pharmacy staff and community pharmacists) would identify if further levers in the system could be influenced to drive PP trust and engagement.

\section{Twitter Hamde Nazar @NazarHamde}

Acknowledgements The authors would like to thank the participants for their time and engagement with this study.

Contributors HN, PW, CW and SK conceived and designed the study. SK undertook the data collection. Data analysis and interpretation was led by SK but with consultation with HN, PW and CW. HN, PW, CW and SK developed the discussion together. SK and HN drafted the first version of the manuscript, and PW and CW reviewed, revised and provided feedback. SK, HN, PW and CW finalised the draft manuscript and all approved the submission.

Funding This research was supported by the Saudi Arabian Cultural Bureau in the UK and Umm Al-Qura University in Saudi Arabia (award/grant number: N/A).

Competing interests None declared.

Patient consent for publication Not required.

Ethics approval This study received ethical approval from the Faculty of Medical Sciences Ethical Committee at Newcastle University (Ref. No. 13444/2018). NHS ethics submission was not required.

Provenance and peer review Not commissioned; externally peer reviewed.

Data availability statement Data are available upon reasonable request. Data from anonymised interviewee transcripts are available on request.

Supplemental material This content has been supplied by the author(s). It has not been vetted by BMJ Publishing Group Limited (BMJ) and may not have been peer-reviewed. Any opinions or recommendations discussed are solely those of the author(s) and are not endorsed by BMJ. BMJ disclaims all liability and responsibility arising from any reliance placed on the content. Where the content includes any translated material, BMJ does not warrant the accuracy and reliability of the translations (including but not limited to local regulations, clinical guidelines, terminology, drug names and drug dosages), and is not responsible for any error and/or omissions arising from translation and adaptation or otherwise.

Open access This is an open access article distributed in accordance with the Creative Commons Attribution Non Commercial (CC BY-NC 4.0) license, which permits others to distribute, remix, adapt, build upon this work non-commercially, and license their derivative works on different terms, provided the original work is properly cited, appropriate credit is given, any changes made indicated, and the use is non-commercial. See: http://creativecommons.org/licenses/by-nc/4.0/.

\section{ORCID iD}

Hamde Nazar http://orcid.org/0000-0002-3168-5386

\section{REFERENCES}

1 National Health Services,, Department of Health. Our health, our care, our say: a new direction for community services, 2006. Available: https://assets.publishing.service.gov.uk/government/ uploads/system/uploads/attachment_data/file/272238/6737.pdf
2 McDowell JRS, McPhail K, Halyburton G, et al. Perceptions of a service redesign by adults living with type 2 diabetes. J Adv Nurs 2009;65:1432-41.

3 Naithani S, Gulliford M, Morgan M. Patients' perceptions and experiences of 'continuity of care' in diabetes. Health Expect 2006;9:118-29.

4 National Health Services. The NHS plan: a plan for investment, a plan for reform, 2000. Available: https://webarchive. nationalarchives.gov.uk/20130123203940/http://www.dh.gov.uk/en/ Publicationsandstatistics/Publications/PublicationsPolicyAndGui dance/DH_4010198

5 Cherry C, Anderson S. National Co-ordinating Centre for NHS Service Delivery and Organisation R\&D, 2002. Available: http://www. netscc.ac.uk/hsdr/files/adhoc/listening-exercise-2002.pdf

6 Royal Pharmaceutical Society (RPS). Hospital referral to community pharmacy: An innovators' toolkit to support the NHS in England, 2014. Available: https://www.rpharms.com/Portals/0/RPS\% 20document\%20library/Open\%20access/Support/toolkit/3649-rpshospital-toolkit-brochure-web.pdf

7 Gunter MJ. The role of the echo model in outcomes research and clinical practice improvement. Am J Manag Care 1999;5:S217-24.

8 Kozma CM, Reeder CE, Schulz RM. Economic, clinical, and humanistic outcomes: a planning model for pharmacoeconomic research. Clin Ther 1993;15:1121-32.

9 Picton C, Wright $\mathrm{H}$. Keeping patients safe when they transfer between care providers - getting the medicines right. final report. London: Royal Pharmaceutical Society, 2012. https://www.rpharms. com/Portals/O/RPS\%20document\%20library/Open\%20access/ Publications/Keeping\%20patients\%20safe\%20transfer\%20of\% 20care\%20report.pdf

10 The National Health Services. The NHS long term plan, 2019. Available: https://www.longtermplan.nhs.uk/publication/nhs-longterm-plan/

11 Discharge medicines review (DMR): community pharmacy Wales Fferylliaeth Gymunedol Cymru. Available: http://www.cpwales.org.uk/ Contract-support-and-IT/Advanced-Services/Discharge-MedicinesReview-(DMR).aspx

12 Dilks S, Emblin K, Nash I, et al. Pharmacy at home: service for frail older patients demonstrates medicines risk reduction and admission avoidance. Clinical Pharmacist 2016;8:1-11.

13 Nazar H, Nazar Z, Portlock J, et al. A systematic review of the role of community pharmacies in improving the transition from secondary to primary care. Br J Clin Pharmacol 2015;80:936-48.

14 Hodson K, Blenkinsopp A, Cohen D, et al. Evaluation of the discharge medicine review service: Welsh Institute for health and social care, 2014. Available: http://www.cpwales.org.uk/Contractsupport-and-IT/Advanced-Services/Discharge-Medicines-Review-( DMR)/Evaluation-of-the-DMR-Service/Evaluation-of-the-DMRservice.aspx

15 Miller D, Ramsey M, L'Hommedieu TR, et al. Pharmacist-Led transitions-of-care program reduces 30 -day readmission rates for Medicare patients in a large health system. Am J Health Syst Pharm 2020;77:972-8.

16 Shaver A, Morano M, Pogodzinski J, et al. Impact of a community pharmacy transitions-of-care program on 30-day readmission. J Am Pharm Assoc 2019;59:202-9.

17 Paulino El, Bouvy ML, Gastelurrutia MA, et al. Drug related problems identified by European community pharmacists in patients discharged from hospital. Pharm World Sci 2004;26:353-60.

18 Lussier ME, Evans HJ, Wright EA, et al. The impact of community pharmacist involvement on transitions of care: a systematic review and meta-analysis. J Am Pharm Assoc 2020;60:153-62.

19 Department of Health and Social Care. New pharmacy referral service to help patients avoid Hospital readmission, 2020. Available: https://www.gov.uk/government/news/new-pharmacy-referralservice-to-help-patients-avoid-hospital-readmission

$20 \mathrm{Nazar} \mathrm{H}$, Brice S, Akhter N, et al. New transfer of care initiative of electronic referral from hospital to community pharmacy in England: a formative service evaluation. BMJ Open 2016;6:e012532.

21 Ferguson J, Seston L, Ashcroft DM. Refer-to-pharmacy: a qualitative study exploring the implementation of an electronic transfer of care initiative to improve medicines optimisation following hospital discharge. BMC Health Serv Res 2018;18:424.

22 Mantzourani E, Way CM, Hodson KL. Does an integrated information technology system provide support for community pharmacists undertaking discharge medicines reviews? an exploratory study. Integr Pharm Res Pract 2017;6:145-56.

23 Moore GF, Audrey S, Barker M, et al. Process evaluation of complex interventions: medical Research Council guidance. BMJ 2015;350:h1258. 
24 Fetters MD, Curry LA, Creswell JW. Achieving integration in mixed methods designs-principles and practices. Health Serv Res 2013;48:2134-56.

25 PRISMA transparent reporting of systematic reviews and metaanalyses, 2015. Available: http://www.prisma-statement.org/

26 Tricco AC, Antony J, Zarin W, et al. A scoping review of rapid review methods. BMC Med 2015;13:224.

27 Ogunbayo OJ, Schafheutle El, Cutts C, et al. Self-Care of longterm conditions: patients' perspectives and their (limited) use of community pharmacies. Int J Clin Pharm 2017;39:433-42.

28 Ellis-Martin M, Street K. An evaluation by patients of pharmacistled medicines management in southern England. Pharm $J$ 2010;284:245-8.

29 Hadi MA, Alldred DP, Briggs M, et al. Effectiveness of a community based nurse-pharmacist managed pain clinic: a mixed-methods study. Int J Nurs Stud 2016;53:219-27.

30 Stewart DC, Maclure K, Bond CM, et al. Pharmacist prescribing in primary care: the views of patients across great Britain who had experienced the service. Int J Pharm Pract 2011;19:328-32.

31 Lee PA, Greenfield G, Pappas Y. Patients' perception of using telehealth for type 2 diabetes management: a phenomenological study. BMC Health Serv Res 2018;18:549.

32 Dale J, Caramlau I, Sturt J, et al. Telephone peer-delivered intervention for diabetes motivation and support: the telecare exploratory RCT. Patient Educ Couns 2009;75:91-8.

33 Bond CS, Worswick L, Management S. Self management and telehealth: lessons learnt from the evaluation of a Dorset telehealth program. Patient 2015;8:311-6.

34 Long AF, Gambling T, Young RJ, et al. Acceptability and satisfaction with a telecarer approach to the management of type 2 diabetes. Diabetes Care 2005;28:283-9.

35 Gulliford MC, Naithani S, Morgan M. Continuity of care and intermediate outcomes of type 2 diabetes mellitus. Fam Pract 2007;24:245-51.

36 Tarrant C, Windridge K, Baker R, et al. 'Falling through gaps': primary care patients' accounts of breakdowns in experienced continuity of care. Fam Pract 2015;32:82-7.

37 Sixsmith J, Callender M, Hobbs G, et al. Implementing the National service framework for long-term (neurological) conditions: service user and service provider experiences. Disabil Rehabil 2014;36:563-72.

38 Cowie L, Morgan M, White P, et al. Experience of continuity of care of patients with multiple long-term conditions in England. J Health Serv Res Policy 2009;14:82-7.

39 Paddison CAM, Saunders CL, Abel GA, et al. Why do patients with multimorbidity in England report worse experiences in primary care? Evidence from the general practice patient survey. BMJ Open 2015;5:e006172.

40 Campbell SM, Kontopantelis E, Reeves D, et al. Changes in patient experiences of primary care during health service reforms in England between 2003 and 2007. Ann Fam Med 2010;8:499-506.

41 Alazri MH, Neal RD, Heywood P, et al. Patients' experiences of continuity in the care of type 2 diabetes: a focus group study in primary care. Br J Gen Pract 2006;56:488-95.

42 Lawton J, Ahmad N, Hanna L, et al. Diabetes service provision: a qualitative study of the experiences and views of Pakistani and Indian patients with type 2 diabetes. Diabet Med 2006;23:1003-7.
43 Walker A, James C, Bannister M, et al. Evaluation of a diabetes referral pathway for the management of hypoglycaemia following emergency contact with the ambulance service to a diabetes specialist nurse team. Emerg Med J 2006;23:449-51.

44 Lawton J, Parry O, Peel E, et al. Diabetes service provision: a qualitative study of newly diagnosed type 2 diabetes patients experiences and views. Diabet Med 2005;22:1246-51.

45 Lawton J, Peel E, Parry O, et al. Lay perceptions of type 2 diabetes in Scotland: bringing health services back in. Soc Sci Med 2005;60:1423-35.

46 Lawton J, Rankin D, Peel E, et al. Patients' perceptions and experiences of transitions in diabetes care: a longitudinal qualitative study. Health Expect 2009;12:138-48

47 Joyce KE, Smith KE, Henderson G, et al. Patient perspectives of condition management programmes as a route to better health, wellbeing and employability. Fam Pract 2010;27:101-9.

48 Gillibrand W. Users' perception of a mobile diabetic eye-screening service. J Diabetes Nurs 2000;4:82-5.

49 Alazri MH, Neal RD. The association between satisfaction with services provided in primary care and outcomes in type 2 diabetes mellitus. Diabet Med 2003;20:486-90.

50 Ritchie J, Lewis J, Mcnaughton Nicholls C, et al. Qualitative Research Practice A guide for social science students \& researchers. Second ed. London: SAGE, 2014.

51 Tong A, Sainsbury P, Craig J. Consolidated criteria for reporting qualitative research (COREQ): a 32-item checklist for interviews and focus groups. Int J Qual Health Care 2007;19:349-57.

52 Saunders B, Sim J, Kingstone T, et al. Saturation in qualitative research: exploring its conceptualization and operationalization. Qual Quant 2018;52:1893-907.

53 Gale NK, Heath G, Cameron E, et al. Using the framework method for the analysis of qualitative data in multi-disciplinary health research. BMC Med Res Methodol 2013;13:117.

54 Lincoln YS, Guba EG, Pilotta JJ. Naturalistic inquiry. Newbury Park, CA: Sage Publications, 1985: 9. 438-9.

55 Shenton AK. Strategies for ensuring trustworthiness in qualitative research projects. Education for Information 2004;22:63-75.

56 Amin MEK, Nørgaard LS, Cavaco AM, et al. Establishing trustworthiness and authenticity in qualitative pharmacy research. Res Social Adm Pharm 2020;16:1472-82.

57 Murray R. Community pharmacy clinical services review: NHS England, 2016. Available: https://www.england.nhs.uk/ commissioning/wp-content/uploads/sites/12/2016/12/communitypharm-clncl-serv-rev.pdf

58 Lam MYY, Dodds LJ, Corlett SA. Engaging patients to access the community pharmacy medicine review service after discharge from Hospital: a cross-sectional study in England. Int J Clin Pharm 2019;41:1110-7.

59 Luetsch K, Rowett D, Twigg MJ. A realist synthesis of pharmacistconducted medication reviews in primary care after leaving Hospital: what works for whom and why? BMJ Qual Saf 2020. doi:10.1136/bmjqs-2020-011418. [Epub ahead of print: 30 Oct 2020].

60 Rogers E. Diffusion of innovations. 5th edn. New York: Free Press, 2003. 